\title{
Pathogen inactivation and by-product formation in a full-scale contact tank
}

\author{
Mehmet Anil Kizilaslan ${ }^{1}$,Ender Demirel ${ }^{1,2^{*}}$, and Mustafa M. Aral ${ }^{2}$ \\ ${ }^{1}$ Eskisehir Osmangazi University, 26480 Eskisehir, Turkey \\ ${ }^{2}$ Design and Simulation Technologies Inc., DSTECH, Eskisehir, Turkey
}

\begin{abstract}
Conventional designs of chlorine contact tanks in potable water treatment plants are insufficient in terms of disinfection efficiency due to low hydraulic and mixing efficiencies. Strong interaction of the turbulent flow with the solid baffles may adversely affect hydraulic, mixing and disinfection performance of the contact system. Recirculating and jet zones created in the tank may require high chlorine dosages to yield adequate disinfection levels, which can result in the formations of high disinfection by-products (DBPs) in the treated water. The use of treated water by the consumers with high chlorine dosages and DBPs may lead to environmental and health problems in the long-term. Disinfection efficiency of the tank can be increased by the modification of the baffles and required disinfection levels can be achieved using lower chlorine dosages. In this study, performance of a patented baffle design is evaluated by means of numerical simulations on a full-scale contact tank. Self-decomposition of the chlorine, pathogen inactivation and formation of Trihalomethane (TTHM) by-product are simulated using a second-order numerical model. Numerical results show that the new baffle design yields $3-\log$ inactivation by using $40 \%$ less chlorine concentration than the conventional design and the amount of DBP can be decreased by $43 \%$.
\end{abstract}

\section{Introduction}

Chlorine Contact Tanks (CCTs) have been used in municipal water treatment plants for the removal of potential pathogens and viruses from the surface and ground waters. CCT in a water treatment plant is conventionally designed as multi-chambered tank, which may result in low hydraulic and mixing efficiencies due to high fluid-solid interaction during the contact time [1]. Surface Water Treatment Rule (SWTR) suggested by the United States Environmental Protection Agency (USEPA) in 1998 recommend 3-log and 4-log inactivation levels for pathogens and viruses, respectively. Development of an efficient contact system may reduce chlorine dosages during the disinfection process, which is of critical importance for health considerations in the treatment of potable waters in cities.

Pathogen inactivation takes place with selfdecomposition of chlorine and disinfection by-products may form during the disinfection process depending on chemical and biological features of the treated water. Disinfection performance of a contact tank can be evaluated with respect to required chlorine dosages for the suggested inactivation level. Numerical modeling of disinfection process based on chemical models is a contemporary issue in the literature. Zhang et al. studied ozone disinfection process in a real-size contact tank using RANS (Reynolds Averaged Navier Stokes) model. Chemical reactions in the disinfection process involved decomposition of ozone, total organic carbon and bromide formations [2]. Angeloudis et al. numerically investigated disinfection performance of several contact tank designs using a first-order chemical model, which provides chlorine self-decomposition, pathogen inactivation and by-product formation [3]. DIVAST (Depth Integrated Velocities and Solute Transport) model was proposed by Zhang et. al. for the disinfection process of ozone [4], which has been used as an effective water treatment method in recent years [5]. Effect of the inlet configuration on the disinfection performance of a contact tank was investigated by Angeloudis et. al. using a first-order chemical model for the chlorine [6]. Kim et al. evaluated the disinfection performance of three different contact tank geometries using both Large Eddy Simulation (LES) and RANS models. The contact tank with the narrow width of the chamber provided the best performance for pathogen inactivation [7].

In this study, hydraulic and mixing efficiencies, as well as disinfection efficiency of a full-scale contact tank in Eskisehir Municipal Water Treatment Plant in Turkey is investigated by means of three-dimensional numerical simulations. A second order disinfection model is developed based on an open source framework [8]. Numerical simulations performed in the present study are analyzed in two stages. Flow simulations were first performed for conventional and patented baffle design. In the second stage of the numerical studies, disinfection simulations were carried out for the chlorine selfdecomposition and pathogen inactivation with focus on the formation of DBP formation.

* Corresponding author: edemirel@ ogu.edu.tr 


\section{Numerical model}

Incompressible and turbulent flow inside the contact tank is governed by the following RANS equations:

$$
\begin{gathered}
\frac{\partial U_{i}}{\partial x_{i}}=0 \\
\frac{\partial U_{i}}{\partial t}+U_{j} \frac{\partial U_{i}}{\partial x_{j}}=-\frac{1}{\rho} \frac{\partial p}{\partial x_{i}}+\frac{\partial}{\partial x_{i}}\left(v \frac{\partial U_{i}}{\partial x_{j}}-\overline{u_{i}^{\prime} u_{j}^{\prime}}\right)
\end{gathered}
$$

where $U_{i}$ is the Reynolds averaged velocity component in the $i$-direction ( $\mathrm{x}, \mathrm{y}$ and $\mathrm{z}$ directions), $p$ is the Reynolds averaged pressure, $t$ is the time, $\rho$ is the fluid density, $v$ is the kinematic viscosity, $x_{i}$ and $x_{j}$ represent Cartesian coordinates. Turbulent flow in the contact tanks is simulated using $k-\varepsilon$ turbulence closure model. Reynolds stresses in this RANS approach can be approximated by the following Boussinesq hypothesis:

$$
-\overline{u_{i}^{\prime} u_{j}^{\prime}}=v_{t}\left(\frac{\partial U_{j}}{\partial x_{i}}+\frac{\partial U_{i}}{\partial x_{j}}\right)+\frac{2}{3} k \delta_{i j}
$$

Where, $\overline{u_{i}^{\prime} u_{j}^{\prime}}$ represents Reynolds stresses, $\delta_{i j}$ is the Kronecker delta, $k$ is turbulence kinetic energy, $v_{t}$ is the turbulent viscosity:

$$
v_{t}=C_{\mu} \frac{k}{\varepsilon^{2}}
$$

Here $\varepsilon$ is the turbulence dissipation rate and $C_{\mu}$ is 0.09 . Two equations are solved for the approximation of $k$ and $\varepsilon$ during the solution of momentum equations. The following turbulence boundary conditions are applied at the inlet:

$$
\begin{aligned}
& k=\frac{3}{2}(U I)^{2} \\
& \varepsilon=C_{\mu}^{3 / 4} \frac{k^{3 / 2}}{l}
\end{aligned}
$$

Here, $U$ is the average flow velocity at the inlet, $I$ is turbulence intensity which is set to 0.05 and $l$ is turbulence length scale. The following advectiondiffusion equations are incorporated into the numerical model for the simulation of chlorine self-decomposition, pathogen inactivation and DBP formation during the disinfection process. Self-decomposition of the chlorine can be modeled using the following equation.

$$
C=C_{\text {injected }} * x * \exp \left(-k_{1}^{\prime} * t+C_{\text {injected }} *(1-x) * \exp \left(-k_{2}^{\prime} * t\right)\right)
$$

$$
k_{1}^{\prime}=a * T O C * \exp (b /(T+273)) * d / C_{\text {injected }}
$$

$k_{2}^{\prime}=e^{*} T O C^{*} \exp (f /(T+273)) * g / C_{\text {injected }}$

$$
\begin{aligned}
& \frac{\partial C_{C l}}{\partial t}+U_{i} \frac{\partial C_{C l}}{\partial x_{i}}=D_{T} \frac{\partial^{2} C_{C l}}{\partial x_{j}^{2}} \\
& -\left(C _ { \text { injected } } * 0 . 5 * \operatorname { e x p } \left(-\left(a * T O C * \exp (b /(T+273)) * d / C_{\text {injected }}\right) * t\right.\right. \\
& \left.\left.+C_{\text {injected }} * 0.5 * \exp \left(-\left(e * T O C * \exp (f /(T+273)) * g / C_{\text {injected }}\right) * t\right)\right)\right) C_{c l}
\end{aligned}
$$

Here $C_{C l}$ represents the chlorine concentration $(\mathrm{mg} / \mathrm{L})$ injected at the inlet, $a, b, d, e, f, g$ are empirical constants, which depend on the organic matter TOC $(\mathrm{mg} / \mathrm{L})$ in the raw water, $T$ is the temperature $\left({ }^{\circ} \mathrm{C}\right)$ and $t$ is contact time (s) in the tank. The empirical constants in the equations were suggested as $a=0.01344 ; \quad b=848 ; d=0.01375$; $e=0.00209 ; f=848$ and $g=4.839$ [9]. Inactivation of Giardia pathogen is expressed using the following advection-diffusion equation.

$\frac{\partial N}{\partial t}+U_{i} \frac{\partial N}{\partial x_{i}}=D_{T} \frac{\partial^{2} N}{\partial x_{j}^{2}}-R C_{C l}^{a} t^{b} p H^{d} T^{e} N$

In this Equation, $R$ value is calculated as $0.32, a=$ $0.726, b=$ is $0.845, d=-2.104$ and $e=0.726$ [10]. DBP formation of TTHM can be defined from the following equation.

$\frac{\partial C_{D B P}}{\partial t}+U_{i} \frac{\partial C_{D B P}}{\partial x_{i}}=D_{T} \frac{\partial^{2} C_{D B P}}{\partial x_{j}^{2}}+0.0325 C_{c t}^{0.517} t^{0.252}$
$\left(T O C^{*} U V_{254}\right)^{0.378}(p H-2.6)^{0.64} T^{0.985}(B r+1)^{0.0535}$

Here $C_{D B P}$ is the total TTHM concentration $(\mu g / l)$, $U V_{254}$ is the $U_{254}$ absorbance of the water $\left(\mathrm{cm}^{-1}\right), B r$ is the bromide concentration $(m g / l)$ and the reaction constants of these parameters were determined from the experimental results reported in [11]. Physical properties of raw water are given in Table 1.

Table 1. Physical properties of raw water

\begin{tabular}{|c|c|c|}
\hline Variable & Value & Dimension \\
\hline $\mathrm{pH}$ & 7 & - \\
\hline $\mathrm{T}$ & 25 & ${ }^{\circ} \mathrm{C}$ \\
\hline $\mathrm{TOC}$ & 8.54 & $\mathrm{mg} / \mathrm{L}$ \\
\hline $\mathrm{UV}_{254}$ & 0.161 & $\mathrm{~cm}^{-1}$ \\
\hline $\mathrm{Br}$ & 1.206 & $\mathrm{mg} / \mathrm{L}$ \\
\hline
\end{tabular}

\section{Simulation setup and boundary conditions}


A block-structured mesh is generated using the standard utility blockMesh in OpenFOAM as shown in Fig. 1. In this approach, blocks are constructed inside the chambers and mesh is refined near the boundaries in order to capture rapid variations in flow variables due to the wall effects. The dimensionless cell size $y+$ near the wall is kept less than 11.6 to ensure that the first cell close to the wall remains in the viscous sublayer. The resultant mesh used in the present simulations consists of 9.72 million cells.

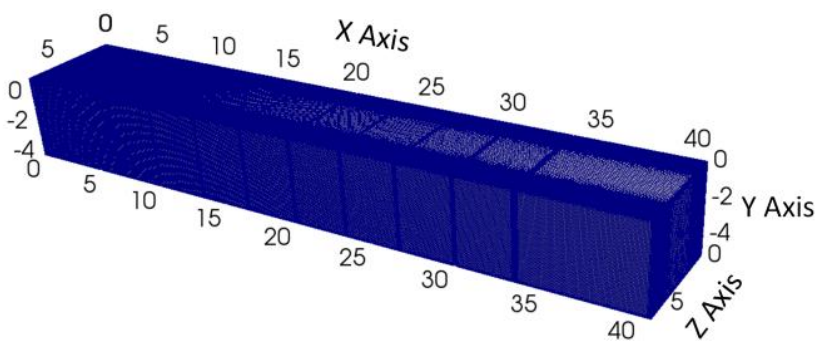

Fig. 1. Computational grid of the contact tank.

Free-stream boundary conditions are applied for all flow variables at the outlet of the computational domain to prevent the reflection of flow variables. No-shear condition is applied for the velocity and zero gradient boundary condition is used for the pressure at walls. Unified wall Appropriate wall functions are employed for the turbulence kinetic energy $\mathrm{k}$, the specific turbulent dissipation rate $\varepsilon$ and the turbulent viscosity $v$ t on the walls. Symmetry boundary condition is applied on the free-surface for all flow variables to impose slip effects since free-surface effects are not considered here. Boundary conditions used in the numerical simulations are given in Table 2.

Chlorine concentration and pathogen number are fixed at the inlet and zero gradient boundary conditions are used at the outlet. Numerical simulations are performed using OpenFOAM on high performance computing center with parallel computing. Entire computational domain is decomposed into 112 subdomains and each subdomain is solved on a different node during the computation. The use of open source code allowed us to develop a new solver for the simulation of reactive chemicals (Eqs. 10, 11 and 12), as well as to perform computational runs on a cloud computing center located in Turkey (High Performance and Grid Computing Center, TRUBA).
Table 2. Boundary conditions

\begin{tabular}{|c|c|c|}
\hline \multirow{2}{*}{ Variable } & Location & BC \\
\hline \multirow{2}{*}{$\mathrm{U}, \mathrm{k}, \mathrm{nut}, \varepsilon$} & inlet & fixedValue \\
\cline { 2 - 3 } & outlet & inletOutlet \\
\cline { 2 - 3 } & top & symmetryPlane \\
\hline \multirow{2}{*}{$\mathrm{p}$} & inlet & zeroGradient \\
\cline { 2 - 3 } & outlet & fixedValue \\
\cline { 2 - 3 } & top & symmetryPlane \\
\cline { 2 - 3 } & walls & zeroGradient \\
\hline \multirow{2}{*}{$\mathrm{U}$} & walls & fixedValue \\
\hline \multirow{2}{*}{$\mathrm{k}$} & walls & kqRWallFunctions \\
\hline \multirow{2}{*}{ nut } & walls & nutkWallFunction \\
\hline \multirow{2}{*}{$\mathrm{E}$} & walls & epsilonWallFunction \\
\hline
\end{tabular}

\section{Results and discussions}

The flowrate passing through the contact tank is set to $160,000 \mathrm{~m}^{3}$ /day for summer conditions since the treated water a day is $160,000 \mathrm{~m}^{3}$ in the corresponding contact tank. The optimized dimensions of the patented slotbaffle design (SBD) used in the contact tank are depicted in Fig 2 [12]. Numerical studies are carried for both conventional and SBD for the simulation of turbulent flow inside the contact tank [1].

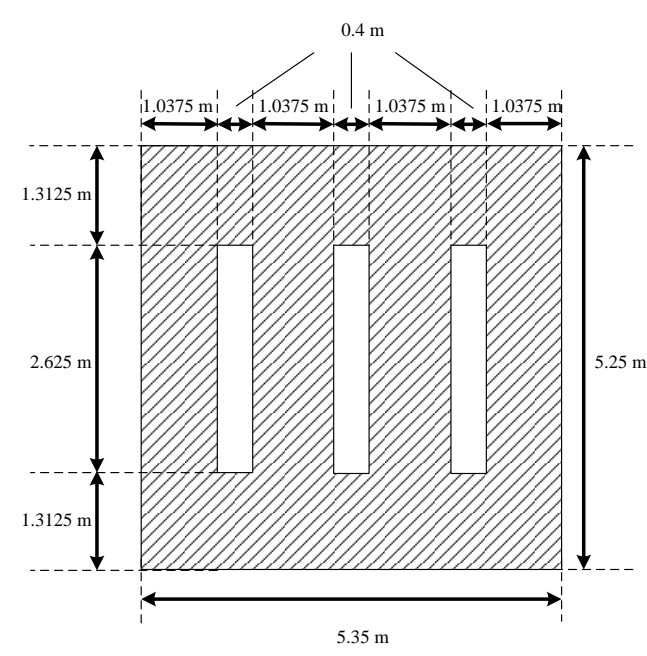

Fig. 2. Slot baffle design.

Disinfection process is simulated using the present computational model for both conventional design (CD) and SBD. Various chlorine concentrations are injected 
from the inlet and pathogen concentration is monitored at the outlet of the tank during the simulation to determine at which concentration of chlorine the suggested 3-log inactivation is achieved [13]. A series of numerical simulations is performed during one Theoretical Residence Time (TRT), which was calculated as 742 seconds for the present tank by the ratio of the wet volume of the tank $\left(1374 \mathrm{~m}^{3}\right)$ to the flow rate $\left(1.852 \mathrm{~m}^{3} / \mathrm{s}\right)$ according to the plug-flow assumption.

Fig.3a depicts variations of pathogen numbers at the outlet of the tank for conventional design and SBD during one TRT. While 3-log inactivation of the Giardia pathogen is achieved using $25 \mathrm{mg} / \mathrm{L}$ chlorine dosage for conventional baffle design, the SBD provided the same inactivation level using $15 \mathrm{mg} / \mathrm{L}$, which is a significant reduction in the chlorine usage. As the injected concentration of chlorine is transported to the outlet of the tank with short-circuiting effects, the decay of pathogen number at the outlet becomes linear for the conventional design. This observation proves that most of the injected disinfectant is transported by high velocity parcels in the conventional design. However, SBD could inactivate pathogens exponentially due to low shortcircuiting effects and high mixing [14-17].

The residual chlorine concentrations observed at the outlet are compared in Fig. 3b. Although chlorine dosages injected at the inlet are significantly different, the residual concentrations are observed identical. Required chlorine dosages are determined according to the measurement of residual chlorine concentrations in water treatment plants. This observation reveals that the injected chlorine could effectively inactivate pathogens using less chlorine dosage in the SBD.

Chemical reactions between chlorine and organic matters in raw water produce disinfection by-products during disinfection process. Figure 4 compares productions of disinfection by-products for conventional and SBD baffles with respect to time during one TRT. Excessive use of chlorine in the conventional design produced larger amount of by-product than the SBD, which is an important adverse effect of using high chlorine dosages to yield desired inactivation levels. Considering the increasing contamination in surface waters nowadays, the use of SBD in water treatment plants can provide significant improvements such as using less chlorine dosages and by-product formations.

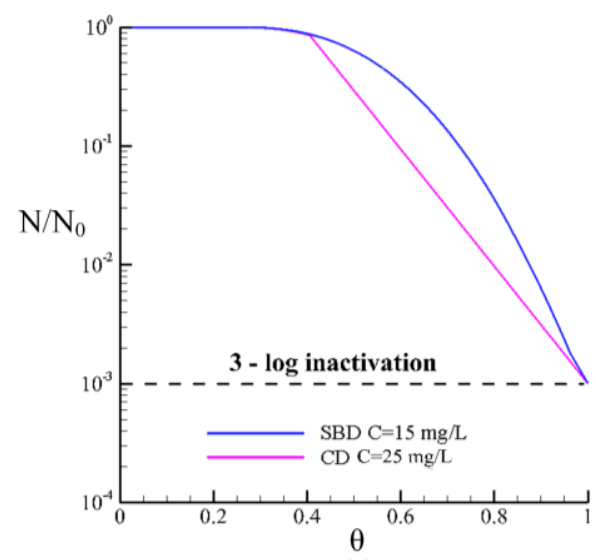

(a)

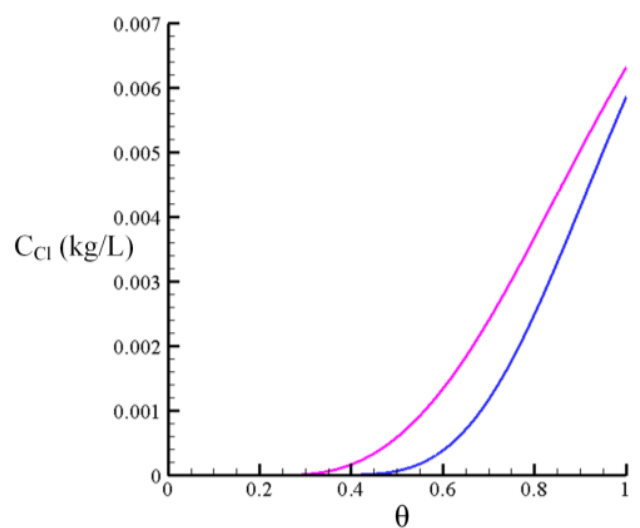

(b)

Fig. 3. a) Pathogen inactivation of conventional and slot baffle designs and b) time variation of residual chlorine during one TRT.

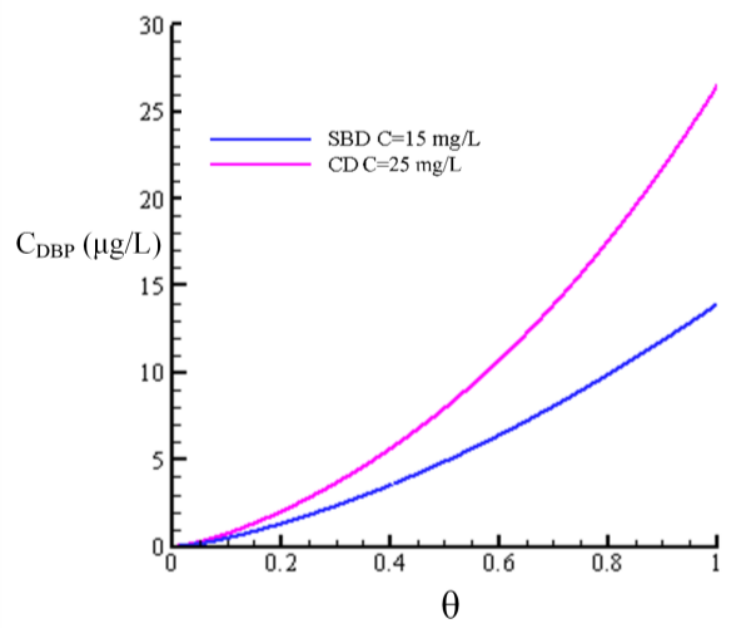

Fig. 4. Disinfection by-product formation of conventional design and SBD.

\section{Conclusions}


Disinfection efficiency of a full-scale chlorine contact tank is investigated based on three-dimensional numerical simulations with special emphasis on the formation of disinfection by-product for two different baffle designs. A second order chemical model is developed and incorporated into the open source code OpenFOAM for the simulation of the disinfection process with respect to the chlorine decay, pathogen inactivation and by-product formation. Following conclusions are drawn from the high-resolution numerical simulations:

1. The patented SBD reduced chlorine dosages by $40 \%$ to provide 3 -log inactivation of Giardia pathogen in the water.

2. A linear pathogen decay is observed at the outlet of the tank when conventional baffle design is used due to short-circuiting effects and low mixing. However, the SBD produces an exponential decay of pathogen at the outlet since the SBD turns the dead zones into active mixing zones which increases mixing and disinfection efficiencies.

3. The second order reaction model of chlorine can be used for the evaluation of disinfection efficiency of an existing contact tank.

4. The SBD can be implemented to an existing contact tank to increase disinfection efficiency and to reduce chlorine dosages to yield suggested inactivation levels.

5. The SBD also reduces amount of by-product formation in water by $43 \%$, which is a significant contribution to the quality of the treated water.

6. Numerical results reveal that the patented baffle design not only increased the disinfection efficiency of the chlorine contact tank but may also reduce the long-term negative health effects due to high dosages of chlorine usage.

This work was supported by the Scientific and Technological Research Council of Turkey (TUBITAK) under Grant no. $217 \mathrm{M} 472$.

\section{References}

1. Kizilaslan, M.A., Demirel E., Aral, M.M. Efficiency Enhancement of Chlorine Contact Tanks in Water Treatment Plants: A Full-Scale Application. Processes 7, 551 (2019)

2. Zhang, J., Tejada-Martínez, A.E., Zhang, Q. Reynolds-averaged Navier-Stokes Simulation of the flow and tracer transport in a multichambered ozone contactor. J. Environ. Eng. 139, 450-454 (2013)

3. Angeloudis, A., Stoesser, T., Falconer, R.A. Predicting the disinfection efficiency range in chlorine contact tanks through a CFD-based approach. Water Res. 60, 118-129 (2014)
4. Zhang, G., Lin, B., Falconer, R.A. Modelling disinfection by-products in contact tanks. J. Hydroinformatics 2, 123-132 (2000)

5. Zhang, J., Tejada-Martínez, A.E., Zhang, Q., Lei, H. Evaluating hydraulic and disinfection efficiencies of a full-scale ozone contactor using a RANS-based modeling framework. Water Res. 52, 155-167 (2014)

6. Angeloudis, A. Contact Tank Design Impact on Process Performance. Environ. Model. Assess. 563$576(2016)$

7. Kim, D., Stoesser, T., Kim, J.H. Modeling aspects of flow and solute transport simulations in water disinfection tanks. Appl. Math. Model. 37, 80398050 (2013)

8. OpenFOAM The OpenFOAM Foundation. OpenCFD Ltd Bracknell UK. (2015)

9. Vieira, P., Coelho, S.T., Loureiro, D. Accounting For The Influence Of Initial Chlorine Concentration, TOC, Iron And Temperature When Modelling Chlorine Decay In Water Supply. J. Water Supply Res. Technol. - AQUA. 53, 453-467 (2003)

10. Clark, R.M. Modeling Inactivation of Giardia. J. Environ. Eng. 116(5), 837-853 (1991)

11. Amy, G.L., Chadik, P.A., Chowdhury, Z.K. Developing Models for Predicting Trihalomethane Formation Potential and Kinetics. J. Am. Water Work. Assoc. 79, 89-97 (1987)

12. Aral, M.M., Demirel, E., A Multi-Chamber SlotBaffle Contact Tank Design; European Patent Office: EP 3339252 A1, Munich, Germany. (2019)

13. United States Environmental Protection Agency. Disinfection profiling and benchmarking guidance manual. Appendix A Rep. No. EPA 816-R-03-004 EPA Cincinnati, USA. (2003)

14. Aral, M.M.; Demirel, E. Novel slot-baffle design to improve mixing efficiency and reduce cost of disinfection in drinking water treatment. J. Environ. Eng. 143, (2017)

15. Demirel, E., Aral, M.M. An efficient contact tank design for potable water treatment. Tech. J. 29, 8279-8294 (2018)

16. Demirel, E., Aral, M.M. Unified analysis of multichamber contact tanks and mixing efficiency based on vorticity field. part I: Hydrodynamic analysis. Water. 8, 495 1-21 (2016)

17. Demirel, E., Aral, M.M. Unified analysis of multichamber contact tanks and mixing efficiency based on vorticity field. part II: Transport analysis. Water. 8, 537, 1-17 (2016) 